RU Концептуальные карты как метод когнитивного обучения на занятиях по иностранному языку в высшей школе

\author{
Шмараева А. А.
}

Аннотация. Цель исследования - выявить дидактический потенциал концептуальных карт в обучении иностранному языку при использовании когнитивного подхода. В статье автор опирается на работы отечественных и зарубежных исследователей и обосновывает применение концептуальных карт с позиций когнитивного обучения. Научная новизна исследования состоит в выдвижении гипотезы о возможности использования концептуальных карт для развития различных видов иноязычной речевой деятельности. В результате исследования была подтверждена связь между составлением концептуальных карт и эффективностью учебной деятельности обучающихся при изучении иностранного языка.

\title{
Concept Maps as a Method of Cognitive Learning in Foreign Language Classes in Higher School
}

\section{Shmaraeva A. A.}

\begin{abstract}
The study aims to identify the didactic potential of concept maps in teaching a foreign language using a cognitive approach. In the article, the author relies on the works of domestic and foreign researchers and substantiates the use of concept maps from the standpoint of cognitive learning. The scientific originality of the research lies in the hypothesis of the possibility of using concept maps for the development of various types of foreign language speech activity. As a result of the study, the connection between the drawing up of concept maps and the effectiveness of the educational activity of students in the study of a foreign language was confirmed.
\end{abstract}

\section{Введение}

Актуальность темы данного исследования обусловлена когнитивным аспектом цели обучения иностранному языку, связанным с мышлением и познавательными процессами, а также психологическими особенностями современных обучающихся. Следует заметить, что Н. Д. Гальскова и Н. И. Гез под когнитивным аспектом понимают «формирование у учащихся умений и навыков использования (творчески, экономно и целенаправленно) рациональных приемов овладения иностранными языками и культурами» [3, с. 115]. Кроме этого, подчеркивается, что когнитивный аспект цели «тесно связывает обучение иностранным языкам с интенсивным использованием его как инструмента познания, развития и овладения языком» [Там же, с. 118]. Безусловно, развивающий аспект обучения неразрывно связан не только с формированием иноязычной коммуникативной компетенции, но и с развитием личностных и познавательных способностей обучающихся, что также является одной из целей обучения. В своей работе Э. Лоарер и М. Юто считают, что «основная цель всех методов когнитивного обучения заключается в развитии интеллекта, а точнее всей совокупности умственных способностей и стратегий, делающих возможным процесс обучения и адаптации к новым ситуациям» [4, с. 17]. Это находит свое отражение в положениях и требованиях федеральных государственных образовательных стандартов высшего образования и, соответственно, в рабочих программах дисциплины «Иностранный язык» в высших учебных заведениях, составляемых на их основе. Цель обучения иностранному языку в высшей школе заключается в формировании и развитии иноязычной коммуникативной компетенции у обучающихся, которая предполагает совершенствование навыков и умений в рецептивных и продуктивных видах речевой деятельности на иностранном языке, а также способности «воспринимать и анализировать научно-популярные сведения и научную информацию... осуществлять устное и письменное межличностное общение» [6, с. 301]. Кроме этого, требованиями ФГОС ВО 3 ++ предусматривается сформированность 
у выпускников бакалавриата и магистратуры определенных универсальных и общепрофессиональных компетенций, касающихся системного и критического мышления, информационно-аналитической деятельности, самоорганизации и саморазвития.

Мы видим, что обучающиеся должны обладать развитым логическим, критическим и творческим мышлением, уметь структурировать большие объемы информации и обладать умением учиться, что является одним из навыков XXI века. Таким образом, здесь мы можем говорить о важном значении когнитивного обучения, которое «основано на таких методах и дидактических способах, которые направлены на развитие рефлексивной мыслительной деятельности учащихся в процессе познания» [1]. Следует также заметить, что «в условиях когнитивного мастерства фокус образовательного процесса направлен не на поглощение информации, а на постижение внутренних отношений исследуемых предметов, побуждает учащихся к диалоговому, исследовательскому размышлению, повышает концентрацию ментальной активности» [Там же].

Немаловажным фактором в контексте рассматриваемой темы являются психологические особенности современных обучающихся высших учебных заведений, которые относятся к поколению Z. Они обладают «способностью осваивать большие объемы информации и находить неординарные решения, эффективно воспринимают краткую и наглядную информацию, отдают предпочтение малым формам визуализации... уделяют большое внимание саморазвитию и самосовершенствованию, различным видам творчества, для них представляет интерес получение знаний и навыков в игровой форме» [8].

Таким образом, преподаватель высшей школы выбирает, адаптирует и использует различные педагогические методы, приемы, формы и средства обучения, которые не только направлены на достижение обучающимися планируемых результатов обучения, предусмотренных рабочими программами, но и способствуют повышению мотивации обучающихся, обеспечению их вовлеченности в учебную деятельность и развитию познавательных способностей. Очевидно, что применение педагогических методов должно быть обусловлено педагогическими условиями и учитывать индивидуально-психологические особенности обучающихся. Одним из эффективных методов, который отвечает вышеназванным требованиям, является, по нашему мнению, составление концептуальных карт, или концепт-карт.

В соответствии с целью данного исследования были поставлены следующие задачи:

- Рассмотреть сущность, особенности концептуальных карт и обосновать эффективность их применения в обучении иностранному языку с позиций когнитивного обучения.

- Определить преимущества, возможные проблемы и факторы, влияющие на эффективность использования данного метода в учебном процессе.

- В соответствии с таксономией Блума определить дидактический потенциал использования концептуальных карт с точки зрения развития всех видов речевой деятельности обучающихся.

Для решения поставленных задач были использованы следующие методы исследования: анализ научной литературы по рассматриваемой проблеме отечественных и зарубежных исследователей; обобщение практического опыта использования концептуальных карт в обучении иностранному языку обучающихся неязыковых факультетов.

Теоретической базой исследования послужили работы Н. Д. Гальсковой, Н. И. Гез [3], Л. В. Ахметовой [1], A. Н. Погребновой [5], Т. А. Сыриной [7], Т. Бьюзена [2], M. A. Almulla, M. M. Alamri [10], J. D. Novak [12], J. Trifone [13], W. Huitt, B. Bloom [11].

Практическая значимость данного исследования заключается в том, что предложенные виды работы с концептуальными картами могут быть использованы на занятиях по иностранному языку для формирования рецептивных и продуктивных видов речевой деятельности, а также повышения вовлеченности обучающихся в учебную деятельность, лучшего понимания и запоминания учебного материала, развития критического и других видов мышления.

\section{Основная часть}

Анализ изученной научной литературы выявил положительное влияние использования концептуальных карт при изучении отдельных дисциплин [5; 10; $12 ; 13]$, так как этот метод напрямую связан с когнитивной визуализацией рассматриваемой информации. Отметим, что «суть когнитивной визуализации заключается в смещении акцента с иллюстративной функции в обучении на развитие познавательных способностей и критического мышления» [7]. Она важна для представления больших объемов информации в краткой, логически выстроенной, схематической форме, способствующей ее пониманию и дальнейшему запоминанию. Дж. Новак подчеркивает, что «концептуальные карты стали важным средством, которое способствует осознанному обучению обучающихся и более эффективной работе преподавателя. Кроме этого, они являются метакогнитивными образовательными технологиями и помогают осознанному осмыслению изучаемого» [12, р. 941] (3десь и далее перевод автора статьи. - А. Ш.). Проведенное им исследование показало, что «концепт-карты помогли им (обучающимся) научиться учиться», а также «оказались полезными при изучении материала, помогли структурировать и понять новые темы» [Ibidem]. Л. В. Ахметова определяет когнитивный процесс как «процесс переработки элементов информации на различных уровнях структурной организации психического аппарата с целью получения некоторого знания» [1] и считает, что «при таком подходе (когнитивном - прим. 
автора) к обучению осознанное и обоснованное рассуждение сопряжено с серьезной и трудной когнитивной работой, способствует высокоэффективному росту мыслительной деятельности» [Там же]. Исследователь отмечает, что «методы когнитивного обучения отличают три основных взаимосвязанных процесса:

1. Мышление-действие, т.е. постановка вопроса, решение проблем в сочетании с разработкой плана действий, систематический поиск оптимальных способов решения задачи.

2. Мышление-размышление, при сочетании интуитивного, образно-смыслового, эмпирического с понятийным и теоретическим. Понимание проблемы, сбор необходимой информации, выдвижение идей, построение гипотез, способность к переносу, рассуждение, умозаключение.

3. Рефлексивное мышление: понимание своей способности выполнить определенную задачу, формирующееся на фоне адекватной самооценки, самостоятельный выбор способов достижения цели и оценка их эффективности» [Там же].

Исходя из вышеизложенного, концептуальные карты можно рассматривать как один из методов когнитивного обучения, направленный на развитие познавательных способностей обучающихся, способствующих произвольному запоминанию, и построенный на принципах деятельностного и личностно ориентированного подходов, наглядности, сознательности, интеграции и дифференциации в обучении.

Следует отметить, что рабочие программы дисциплины «Иностранный язык» в высшей школе предполагают рассмотрение и обсуждение разных профессионально-ориентированных тем, которые сопровождаются изучением объемных специализированных текстов (на 2 и 3 курсах бакалавриата и 1 курсе магистратуры) и общей тематической направленности (1 курс бакалавриата) [6]. В связи с этим, концептуальные карты, которые представляют собой иерархические карты-схемы взаимосвязей основных идей (концептов), являются эффективным способом не только знакомства и понимания изучаемой информации, но и запоминания, воспроизведения, а также осуществления контроля изученного материала.

Напомним, что концептуальная карта представляет собой иерархическую пирамиду, вершину которой занимает общая идея или концепт. Далее от нее отходят линии, соединяющие ключевое понятие (концепт) со связанными с ним идеями (концептами) второго порядка, которые, в свою очередь, соединяют идеи второго порядка с более конкретными, уточняющими понятиями (концептами) третьего порядка и т.д. (Схема 1). В процессе работы с информацией происходит определение более значимых и менее значимых сведений, относящихся к рассматриваемой теме, в результате которого обучающиеся получают иерархическую структуру ключевых идей, значимых для понимания этой темы. Неотъемлемой частью концептуальной карты являются связующие слова или фразы, которые располагаются на линиях, соединяющих понятия разного порядка. Второстепенные концепты могут быть связаны как с общим концептом, так и между собой. Полученная концептуальная карта является наглядной схемой ключевых идей (концептов) рассматриваемой темы и взаимосвязей между ними. Такие концептуальные карты представляют собой содержательные и, в некоторой степени, языковые опоры при ответе обучающихся.

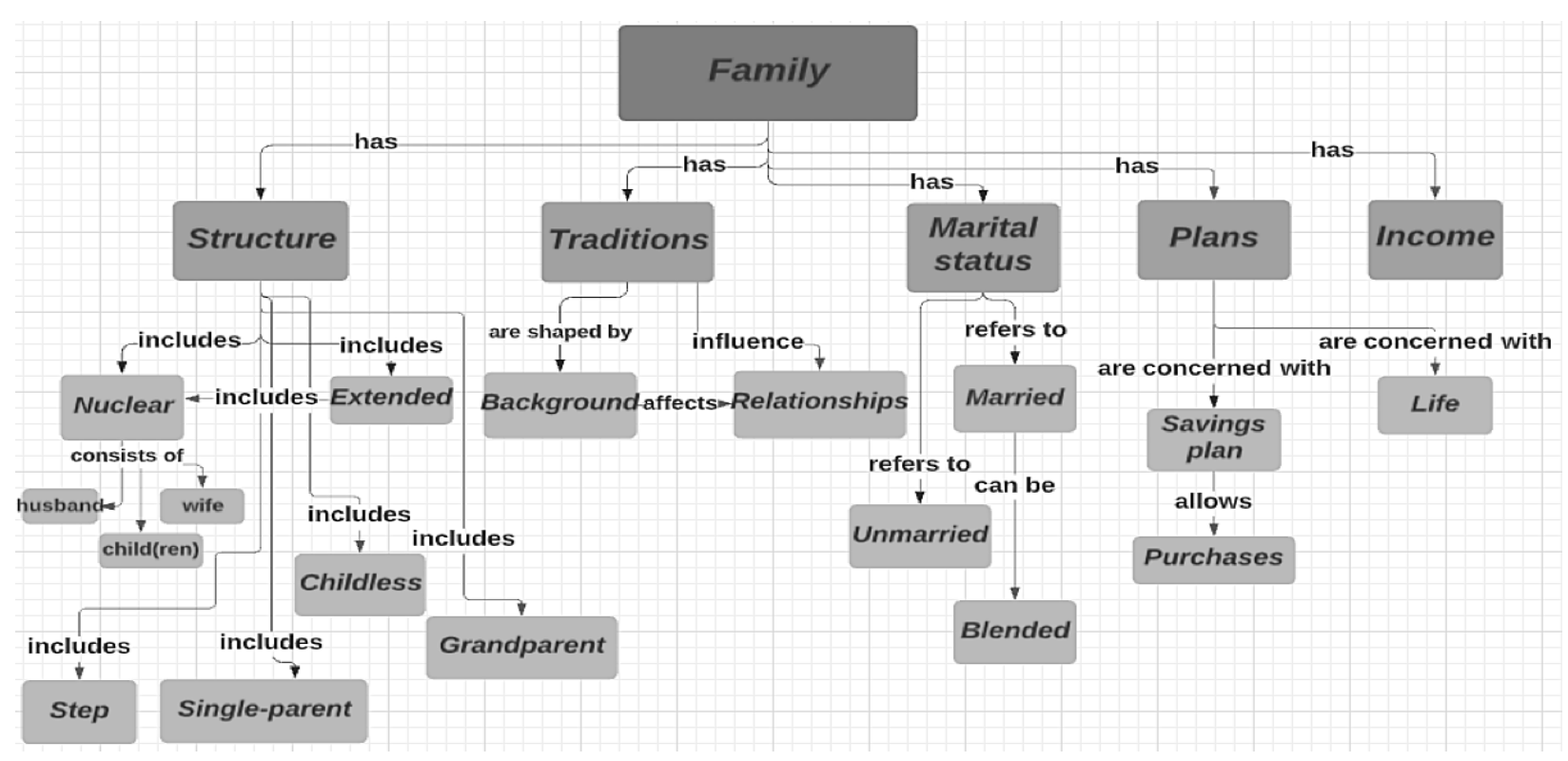

Схема 1

Таким образом, при составлении концептуальных карт задействуются следующие мыслительные операции: анализ, сравнение, классификация, абстракция, обобщение и конкретизация. Действительно, мыслительные процессы, которые актуализируются во время составления концептуальных карт, дают нам основание утверждать, что такой вид учебных заданий развивает не только критическое и логическое мышление, но и умение учиться, поскольку он связан с внутренней мотивацией, учебной автономией обучающихся, 
стимулирует познавательную деятельность, развивает у обучающихся усидчивость, способность концентрироваться, выделять главное и второстепенное, что ведет к осознанному обучению.

Исследователи отмечают [5; 10; 12; 13], что концептуальные карты используются в обучении для повышения мотивации и успеваемости обучающихся. Кроме этого, они «способствуют усвоению информации благодаря наглядному формату; помогают разобраться в общей картине благодаря выработке новой информации в результате объединения новых и старых идей; позволяют доступно объяснять сложные идеи; способствуют совместному обучению; развивают творческое мышление; отображают текущий уровень понимания темы, что полезно для оценки собственных знаний; выявляют области, где требуются дополнительные знания или повторение» [9]. Следовательно, концептуальные карты могут рассматриваться в качестве средства повышения учебной мотивации, которая ведет к развитию внутренней мотивации, что способствует повышению качества обучения. Кроме этого, Т. Бьюзен, создатель методики «карты мыслей», считает, что «благодаря сочетанию вербальных и визуальных средств и отражению мыслительного процесса мозга в части логического и творческого результата интеллект-карта представляет собой идеальный инструмент мышления в условиях глобализированного XXI века» [2, с. 48].

Наряду с положительными сторонами применения данного метода можно отметить возможные проблемы при его использовании. Во-первых, ввиду психологических особенностей современных обучающихся, в частности, клипового мышления, они не способны к концентрации на предмете изучения в течение продолжительного времени. В связи с этим процесс обработки информации или объемного текста может вызвать трудности у обучающихся, так как он предполагает внимательное изучение текста, выделение ключевых идей и установление смысловых связей. Во-вторых, построение концептуальных карт основано на знании определенных лексических единиц изучаемого языка, а обсуждение темы с опорой на составленную карту означает владение средствами логической связи, словами и словосочетаниями, изученными в рамках данной темы или ранее. В связи с этим в случае недостаточного лексического запаса у обучающихся могут возникнуть трудности при описании идей и характеристики их связей. В-третьих, учебное задание должно отвечать принципам посильности, доступности, интеграции и соответствовать поставленным учебным целям, что должно учитываться преподавателем при планировании занятий. В-четвертых, «формальный подход» обучающихся к составлению концептуальных карт и отсутствие осознанности при их построении ведет к обесцениванию их использования в учебном процессе и не приносит планируемого преподавателем результата.

В результате обобщения практического опыта использования концептуальных карт мы может сделать вывод о том, что существуют факторы, которые влияют на эффективность их использования в учебном процессе. Этими факторами являются:

1. Ясные и подробные объяснения преподавателя о принципах построения концептуальных карт. Они важны для понимания обучающимися процесса их составления и дальнейших результатов их использования.

2. Учебная мотивация и вовлечение в учебную деятельность. Преподаватель организует учебный процесс таким образом, чтобы составление концептуальных карт было интересно как обучающимся с высокой степенью самоорганизации, так и с низкой. Таким образом, преподаватель создает положительные мотивы для обеспечения вовлеченности всех обучающихся и осознанного выполнения предлагаемого задания, учитывая их личностные качества.

3. Количество человек в группе. В зависимости от количества обучающихся в группе можно выбрать любой режим работы, но мы считаем наиболее эффективной парную или групповую работу, поскольку в данном случае задействуются разные виды речевой деятельности.

4. Время. При планировании занятия преподаватель должен определить время, отводимое на выполнение данного вида задания, и решить, насколько оправданным является его использование на том или ином занятии.

Однако мы считаем, что любой обучающийся при работе с концептуальными картами получает положительный опыт, так как они «заставляют тренировать тот тип мышления, который развит слабее и, следовательно, способствует более гармоничному когнитивному развитию личности и повышает эффективность процесса обучения» [5]. В связи с этим учебные задания, предполагающие составление концептуальных карт, можно использовать в любой учебной группе.

Подводя итог, можно заметить, что возможные проблемы при использовании концептуальных карт в учебном процессе легко преодолимы и виден очевидный положительный эффект от их применения на занятиях по иностранному языку. В результате составления концептуальных карт у обучающихся происходит более эффективное усвоение учебного материала благодаря активизации различных мыслительных процессов, а также формируется графическая схема ключевых идей изучаемой темы, которая впоследствии может быть использована для повторения материала.

В соответствии с таксономией учебных целей, предложенной Б. Блумом, в которой к навыкам мышления высшего порядка относятся синтез и оценка [11], рассмотрим каждый вид речевой деятельности и соответствующие ему учебные задания с точки зрения актуализации конкретных мыслительных процессов при создании концептуальных карт.

Приведем таблицу (см. Таблица 1) соотнесения видов учебных заданий и уровней мыслительных процессов, которые задействуются при составлении концептуальных карт в процессе обучения аудированию, говорению, чтению и письму (на основе классификации Н. Д. Гальсковой и Н. И. Гез [3]). 
Таблица 1. Учебные задания на каждый вид речевой деятельности и соответствующие им уровни мыслительных процессов при составлении концептуальных карт

\begin{tabular}{|c|c|c|}
\hline Вид речевой деятельности & Вид учебных заданий & $\begin{array}{c}\text { Уровни мыслительных процессов, } \\
\text { которые задействуются } \\
\text { при составлении концептуальных карт }\end{array}$ \\
\hline $\begin{array}{l}\text { Аудирование } \\
\text { (для уровней общего, полного } \\
\text { и критического понимания) }\end{array}$ & $\begin{array}{l}\text { 1. В качестве тренировочного/подготови- } \\
\text { тельного упражнения. } \\
\text { 2. В качестве речевого упражнения: } \\
\text { a) для частично управляемого обучения } \\
\text { аудированию: } \\
\text { - для прогнозирования или в качестве } \\
\text { вербальных зрительных опор; } \\
\text { - на основе прослушанной информации; } \\
\text { б) для неуправляемого обучения аудиро- } \\
\text { ванию (на основе прослушанной инфор- } \\
\text { мации); } \\
\text { в) для развития умений смысловой пере- } \\
\text { работки и фиксации воспринятой на слух } \\
\text { информации (на основе прослушанной } \\
\text { информации). }\end{array}$ & $\begin{array}{l}\text { 1. Знание, анализ, синтез, оценка. } \\
2 . \\
\text { а) } \\
\text { - знание, анализ, синтез, оценка; } \\
\text { - понимание, применение, анализ, } \\
\text { синтез, оценка; } \\
\text { б) понимание, применение, анализ, } \\
\text { синтез, оценка; } \\
\text { в) понимание, применение, анализ, } \\
\text { синтез, оценка. }\end{array}$ \\
\hline $\begin{array}{l}\text { Говорение } \\
\text { (для обучения подготовленным } \\
\text { монологическим и диалогическим } \\
\text { высказываниям) }\end{array}$ & $\begin{array}{l}\text { Индивидуальные, парные и групповые ви- } \\
\text { ды заданий коммуникативной направлен- } \\
\text { ности на уровне: } \\
\text { 1. Подготовительных/тренировочных уп- } \\
\text { ражнений (при обсуждении тем или плани- } \\
\text { ровании монологического высказывания). }\end{array}$ & 1. Знание, анализ, синтез, оценка. \\
\hline Чтение & $\begin{array}{l}\text { 1. Ознакомительное: } \\
\text { а) для прогнозирования перед чтением } \\
\text { текста; } \\
\text { б) после чтения для контроля понимания } \\
\text { основной информации. } \\
\text { 2. Изучающее: } \\
\text { а) в качестве задания перед чтением; } \\
\text { б) после чтения для контроля понимания. }\end{array}$ & $\begin{array}{l}\text { 1. } \\
\text { а) знание, анализ, синтез, оценка; } \\
\text { б) понимание, применение, анализ, } \\
\text { синтез, оценка. } \\
2 . \\
\text { а) знание, анализ, синтез, оценка; } \\
\text { б) понимание, применение, анализ, } \\
\text { синтез, оценка. }\end{array}$ \\
\hline Письмо & $\begin{array}{l}\text { 1. Репродукция содержания с опорой } \\
\text { на текст. } \\
\text { 2. Продукция с опорой на изобразитель- } \\
\text { ную наглядность или на прежний речевой } \\
\text { и жизненный опыт. } \\
\text { 3. При составлении плана для развернуто- } \\
\text { го или свободного изложения, написании } \\
\text { сочинения или изложения. } \\
\text { 4. При реферировании или аннотировании. }\end{array}$ & $\begin{array}{l}\text { 1. Понимание, применение, анализ, } \\
\text { синтез, оценка. } \\
\text { 2. Знание, анализ, синтез, оценка. } \\
\text { 3. Понимание, применение, синтез, } \\
\text { оценка. } \\
\text { 4. Понимание, применение, анализ, } \\
\text { синтез, оценка. }\end{array}$ \\
\hline
\end{tabular}

Как видно из Таблицы 1, в процессе составления концептуальных карт активизируются мыслительные процессы низшего (знание) [11], среднего (понимание, применение, анализ) и высшего порядка (синтез и оценка) [Ibidem]. Следует обратить внимание на то, что во всех рассмотренных видах учебных заданий с использованием концептуальных карт задействуются высшие уровни мыслительных процессов, что позволяет нам сделать вывод о том, что они обладают достаточно большим дидактическим потенциалом и могут эффективно использоваться при обучении рецептивным и продуктивным видам речевой деятельности. Кроме этого, применение концептуальных карт на занятиях по иностранному языку способствует интенсификации обучения, лучшему пониманию изучаемого материала благодаря его структурированию и эффективному воспроизведению обучающимися в дальнейшем. Исходя из вышеизложенного, концептуальные карты могут применяться на начальном, среднем и продвинутом этапах обучения. Таким образом, мы считаем, что они способствуют развитию когнитивных способностей обучающихся, которые критически значимы для успешности обучающихся не только в случае овладения иностранным языком, но и, в широком смысле, в будущей профессиональной деятельности.

\section{Заключение}

В процессе проведения исследования анализ научной литературы выявил положительное влияние использования концептуальных карт при изучении отдельных дисциплин, в том числе иностранного языка, 
и дал возможность утверждать, что концептуальные карты можно рассматривать в качестве метода когнитивного обучения. Наше исследование определило возможные проблемы и факторы, влияющие на эффективность использования концептуальных карт в учебном процессе, и был сделан вывод о том, что перечисленные трудности могут быть предупреждены или сведены к минимуму в случае устранения причин их возникновения. Кроме этого, к преимуществу данного метода была отнесена возможность его использования в любой учебной группе и на любом этапе обучения, так как он способствует глубокому пониманию содержательной информации учебной темы обучающимися и установлению смысловых связей как в рамках изучаемой проблематики, так и с опорой на фоновые знания.

Проведенное соотнесение отдельных видов учебных заданий с уровнями мыслительных процессов в соответствии с таксономией учебных целей Б. Блума, которые задействуются при создании концептуальных карт, позволило сделать вывод о том, что они обладают значительным дидактическим потенциалом, то есть концептуальные карты могут применяться в качестве подготовительных, заключительных, контрольных заданий при формировании и развитии аудитивных, устно-речевых, письменных навыков и умений, а также навыков чтения при изучении текстов различных жанров и объемов на занятиях по иностранному языку. Исследование подтвердило немаловажную роль концептуальных карт в повышении эффективности и качества усвоения знаний обучающимися, развитии когнитивных способностей, критического, логического и творческого видов мышления и наличие связи между выполнением учебных заданий, требующих составления концептуальных карт, и степенью успешности освоения различных видов иноязычной речевой деятельности. Благодаря тому, что концептуальные карты представляют собой когнитивную стратегию, задействующую разные уровни мыслительных процессов, их применение на занятиях по иностранному языку способствует не только эффективному усвоению учебного материала и более легкому его воспроизведению, осознанному обучению, большей самостоятельности обучающихся в их учебной деятельности, но и ведет к повышению мотивации и их личностному развитию.

Перспективы дальнейшего исследования будут связаны с определением перечня и дидактического потенциала цифровых образовательных инструментов для составления концептуальных карт и последующим анализом результатов их использования в обучении иностранному языку в высшей школе.

\section{Источники | References}

1. Ахметова Л. В. Когнитивная сфера личности психологическая основа обучения [Электронный ресурс]. URL: https://cyberleninka.ru/article/n/kognitivnaya-sfera-lichnosti-psihologicheskaya-osnova-obucheniya (дата обращения: 05.08.2021).

2. Бьюзен Т. Интеллект-карты: полное руководство по мощному инструменту мышления. М.: Манн, Иванов и Фербер, 2018. 208 с.

3. Гальскова Н. Д., Гез Н. И. Теория обучения иностранным языкам: Лингводидактика и методика: учебное пособие для студентов лингвистических университетов и факультетов иностранного языка высших педагогических учебных заведений. Изд-е 2-е, испр. М.: Академия, 2005. 336 с.

4. Лоарер Э., Юто М. Когнитивное обучение: история и методы // Когнитивное обучение: современное состояние и перспективы / под ред. Т. Галкиной, Э. Лоарера. М.: Институт психологии РАН, 1997. С. 17-33.

5. Погребнова А. Н. Концепт-карта как инструмент познания в контексте развития навыков 21 века [Электронный ресурс]. URL: https://mgimo.ru/upload/iblock/939/koncept-karta-kak-instrument-poznaniya-vkontekste-razvitiya-navykov-21-veka.pdf (дата обращения: 05.08.2021).

6. Программы по английскому языку для гуманитарных факультетов: сборник программ курсов / под общ. ред. д. пед. н., проф. В. В. Сафоновой. М.: Наука, 2020. 642 с.

7. Сырина Т. А. Когнитивная визуализация: сущность понятия и его роль в обучении языку [Электронный pecypc]. URL: https://cyberleninka.ru/article/n/kognitivnaya-vizualizatsiya-suschnost-ponyatiya-i-ego-rol-vobuchenii-yazyku (дата обращения: 05.08.2021).

8. Хангельдиева И. Г. Цифровая эпоха: возможно ли опережающее образование? [Электронный ресурс]. URL: https://cyberleninka.ru/article/n/tsifrovaya-epoha-vozmozhno-li-operezhayuschee-obrazovanie (дата обращения: 10.05.2021).

9. Что такое концептуальная карта и как ее создать? [Электронный ресурc]. URL: https:/www.lucidchart.com/ pages/ru/концептуальная-карта/\#section_0 (дата обращения: 07.08.2021).

10. Almulla M. A., Alamri M. M. Using Conceptual Mapping for Learning to Affect Students' Motivation and Academic Achievement [Электронный ресурс]. URL: https://www.mdpi.com/2071-1050/13/7/4029/htm (дата обращения: 10.08.2021).

11. Huitt W. Bloom et al.’s Taxonomy of the Cognitive Domain [Электронный ресурc]. URL: http://www.edpsycinter active.org/topics/cognition/bloom.html (дата обращения: 10.08.2021).

12. Novak J. D. Concept mapping: a useful tool for science education // Journal of Research in Science Teaching. 1990. Vol. 27. № 10. P. 937-949.

13. Trifone J. The Effect of Concept Mapping on Changes in Motivation and Self-Regulation as a Function of Learners' Goal Orientation [Электронный ресурс]. URL: https://www.academia.edu/2940712/The_Effect_of_Concept_ Mapping_on_Changes_in_Motivation_and_Self_Regulation_as_a_Function_of_Learners_Goal_Orientation (дата обращения: 10.08.2021). 


\section{Информация об авторах | Author information}

\section{RU Шмараева Анастасия Александровна}

${ }^{1}$ Московский государственный университет имени М. В. Ломоносова

\section{EN Shmaraeva Anastasia Aleksandrovna ${ }^{1}$}

${ }^{1}$ Lomonosov Moscow State University

${ }^{1}$ shmaraeva@gmail.com

\section{Информация о статье | About this article}

Дата поступления рукописи (received): 24.08.2021; опубликовано (published): 30.09.2021.

Ключевые слова (keywords): концептуальные карты; когнитивное обучение; когнитивная визуализация; обучение иностранному языку; эффективность обучения; concept maps; cognitive learning; cognitive visualization; teaching a foreign language; learning efficiency. 